\title{
Keefektifan Kegiatan Bongkar Muatan General Cargo Pt. Atho Tama di Pelabuhan Tanjung Priok Jakarta
}

\author{
Robinsar Yuliando ${ }^{1 *}$, Himawan Aditya Pratama ${ }^{2}$
}

${ }^{1}$ Alumni Prodi MTL, Sekolah Tinggi Maritim Yogyakarta, Jl. Magelang KM 4.4, ${ }^{2}$ Sekolah Tinggi Maritim Yogyakarta, Jl. Magelang KM 4.4, Kutu Dukuh, Sinduadi, Kec. Mlati, Kabupaten Sleman,

*Corresponding Author.E-mail:himawan.aditya.pratama@gmail.com.Telp:081227522776

\begin{abstract}
Abstrak
Ada lima komponen utama yang mempengaruhi kinerja pelabuhan yaitu: Gerakan kapal, produktivitas tenaga kerja, peralatan, intensitas muatan di tambatan, dan intensitas arus muatan di lokasi penyimpanan. Kelima komponen tersebut mempengaruhi keefektifan kegiatan bongkar muat di pelabuhan. Dalam menganalisis data penulis menggunakan metode kualitatif dalam menganalisa sebuah data yang ada dilapangan. Faktor yang sangat mempengaruhi keterlambatan atau menghambat kegiatan pembongkaran yaitu ketika proses membongkar Cargo; kapal melakukan ballast; cuaca yang buruk. Proses pembongkaran muatan General Cargo berkinerja dengan pedoman safety cargo, yang mengutamakan keselamatan dalam kinerja bongkar muat yaitu ke cargo. Setiap kapal lebih mementingkan keselamatan kerja namun disisi lain pihak kapal lebih lagi mementingkan keamanan muatan ketika sedang mengoperasikan pembongkaran ke dermaga maupun ke tongkang(barge).
\end{abstract}

Kata Kunci: Keefektifan, Kinerja, Bongkar muat, Cargo

\begin{abstract}
There are five main components that affect port performance, namely: Ship movement, labor productivity, equipment, cargo intensity at moorings, and cargo flow intensity at storage locations. (media.neliti.com, 2019). These five components affect the effectiveness of loading and unloading activities at the port. In analyzing the data the author uses qualitative methods in analyzing a data that is in the field. Factors that greatly affect delays or hinder unloading activities are when the process of unloading cargo; the ship performs ballast; bad weather. General Cargo's unloading process performs with cargo safety guidelines, which prioritize safety in loading and unloading performance, namely to cargo. Every ship is more concerned with work safety, but on the other hand, the ship is more concerned with cargo safety when operating the unloading to the dock or to the barge.
\end{abstract}

Keywords: Effectiveness, Performance, Loading and unloading, Cargo 


\section{PENDAHULUAN}

Seiring dengan pertumbuhan dan perkembangan ekonomi terutama dalam masalah perniagaan dimana kegiatan tersebut semakin meningkat dan berkembang pesat yang tidak mungkin lepas lagi dari penggunaan sektor transportasi yang mencakup bidang angkutan laut. Transportasi laut sebagai penunjang kelancaran perniagaan untuk mengantar barang ke konsumen. Perkembangan pelabuhan akan sangat ditentukan oleh perkembangan aktivitas perdagangannya. Semakin ramai aktivitas perdangangan di pelabuhan tersebut maka akan semakin besar pelabuhan tersebut. (Suyono, R. P. $2005: 4$ ).

Ada lima komponen utama yang mempengaruhi kinerja pelabuhan yaitu: Gerakan kapal, produktivitas tenaga kerja, peralatan, intensitas muatan di tambatan, dan intensitas arus muatan di lokasi penyimpanan. (media.neliti.com, 2019).

Kelima komponen tersebut mempengaruhi keefektifan kegiatan bongkar muat di pelabuhan. Kegiatan bongkar muat kapal yang mengalami keterlambatan akan merugikan pihak ekspedisi kerena kapal yang bersandar di pelabuhan harus membayar sewa per harinya. Hal yang utama adalah peralatan, peralatan dalam proses bongkar muat sangat diperlukan dalam mendukung dan melaksanakan kegiatan bongkar muat tersebut. Dalam terminal curah kering merupakan terminal khusus yang melayani aktivitas bongkar muat barang curah kering yang biasanya identik dengan barang padat seperti pallet, bundle, Coils, Garam, dan lain sebagainya. (media.neliti.com, 2019).

Faktor peralatan pada pelabuhan mempunyai faktor dominan dalam menentukan proses bongkar muat. Tanpa peralatan bongkar muat yang memadai, maka proses bongkar muat akan menjadi terkendala. Variabel peralatan sebagai penyebab keterlambatan bongkar muat sangat banyak, namun belum semuanya dianalisa secara detail. Oleh sebab itu perlu di lakukan sebuah Analisa untuk mengetahui faktor dominan terjadinya keterlambatan bongkar muat akibat peralatan tersebut.

Dari latar belakang masalah tersebut maka perlu adanya sarana dan prasarana untuk meningkatkan efisiensi di dalam perdagangan terutama jalur transportasi laut, sehingga dibutuhkan profesionalisme di dalam penanganan jasa angkutan laut khususnya muatan general cargo.

Dalam hal ini, penyusun akan membahas tentang segala hal mengenai keefektifan pembongkaran khususnya Curah Kering sesuai judul, Keefektifan Jasa Bongkar Muatan PT. Atho Tama dalam Pembongkaran General Cargo di Pelabuhan Tanjung Priok.

\section{KAJIAN LITERATUR}

\section{A. Keefektifan Bongkar Muat}

Menurut Mahmudi (2005), "Efekivitas merupakan hubungan antara output dengan tujuan, semakin besar kontribusi (sumbangan) output terhadap pencapaian tujuan, maka semakin efektif organisasi, program atau kegiatan"

Keefektifan pembongkaran muatan dalam kinerja lapangan yang melakukan pembongkaran Ship to Ship maupun Kapal ke dermaga (Warehouse) perporos pada 
cepat lambatnya kegiatan yang harus disesuaikan, agar tidak terjadinya kerugian bagi pemakai jasa. Besar manfaatnya bagi pemakai jasa dalam memperhitungkan cepat lambatnya proses Pembongkaran yang di kinerjakan pihak PBM, kualitas serta pelayanan yang kurang akan berpengaruh besar terhadap produksi pembongkaran.

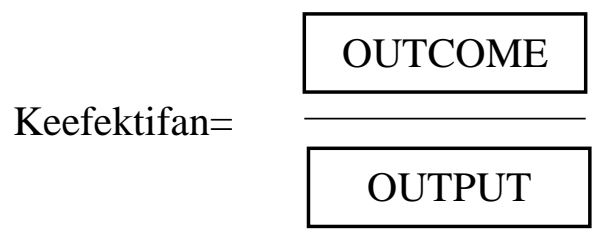

Berdasarkan dengan gambar di atas, maka keefektifan menggambarkan antara input, proses dan output. Mengacu pada hasil guna suatu organisasi, program atau kegiatan yang menyatakan sejauh mana tujuan (kualitas, kuantitas, dan waktu) telah dicapai, serta ukuran berhasil tidaknya suatu organisasi mencapai tujuannya dan mencapai target- targetnya.

\section{B. Kegiatan Bongkat Muat}

Menurut Suyono R. P. (2005 : 310 - 311), perusahaan bongkar muat (PBM) adalah perusahaan yang secara khusus berusaha di bidang bongkar muat dari dan ke kapal, baik dari dan ke Gudang lini satu maupun langsung ke alat angkutan yang meliputi kegiatan :

1. Stevedoring

Stevedoring adalah perkerjaan membongkar barang dari kapal ke demarga, tongkang, truk dan atau memuat barang dari ke dermaga, tongkang, truck kedalam kapal sampai dengan tersusun ke dalam palka kapal dengan menggunakan derek kapal atau derek laut.

2. Cargodoring

Cargodoring adalah pekerjaan melepaskan barang dari tali atau jala-jala (extackle) di dermaga dan mengangkut dari dermaga ke Gudang atau lapangan penumpukan selanjutnya menyusun di Gudang atau lapangan penumpukan atau sebaliknya.

3. Receiving/Delivery

Receving/Delivery adalah pekerjaan memindahkan barang dari timbunan atau tempat penumpukan di Gudang atau lapangan penumpukan dan menyerahkan sampai tersusun di atas kendaraan di pintu Gudang atau lapangan penumpukan atau sebaliknya. (Suyono, R. P. 2005 : 310 - 311).

C. Indikator Kinerja

Key performance indicator (KPI) adalah paramenter atau ukuran pencapaian target yang ditetapkan meliputi pelayanan terhadap kapal hasil bongkar muat barang, pemakaian fasilitas dan peralatan pelabuhan. (D. A. Lasse, $2016: 115$ $125)$. 


\section{Service Terhadap Kapal}

Pelayanan kapal diukur dari satuan waktu, yakni berapa lama kapal berada diterminal dan pelabuhan untuk melaksanakan bongkar muat barang. Waktu kapal di terminal atau dermaga adalah berthing time. Dihitung sejak ikat tali pertama di dermaga sampai lepas tali terakhir dermaga. Waktu kerja bongkar muat adalah Operational Time atau Berth Working Time (BWT), waktu sesungguhnya bongkar muat berlangsung adalah Effective Time. Dalam kunjungan kapal kepelabuhan ada tiga kategori waktu yang apabila tidak dikendalikan berakibat kontra produktif, yakni:

a) Waktu tunggu fasilitas bertambah dan pelayanan pandu dan tunda atau waiting time.

b) Waktu jadwal tanpa kegiatan atau non operational time.

c) Waktu berhenti operasi bongkar muat atau idle time yang terjadi sewaktu- waktu ketika alat tidak siap menunggu muatan, cuaca buruk dan pergantian shift.

2. Ouput Bongkar Muat

Hasil bongkar muat barang dari dan ke kapal yang diukur dalam satuan ton per jam atau ton per jam shift, atau ton per hari. Berdasarkan terminology internasional ouput ini menggunakan tolak ukur berth troughput.

\section{Utilization Fasilitas dan Peralatan}

Tolak ukur atas pemakaian fasilitas dan peralatan disebut utilisasi yakni rasio pemakaian fasilitas pokok meliputi dermaga, Gudang atau lapangan, peralatan apung dan bongkar muat. (D. A. Lasse, 2016 : 115 - 125).

\section{METODE PENELITIAN}

Dalam menganalisis data penulis menggunakan metode kualitatif dalam menganalisa sebuah data yang ada dilapangan. Metode Penelitian Kualitatif adalah suatu metode riset yang bersifat deskriptif dengan memakai analisis, mencari data, dan memanfaatkan teori yang ada sebagai bahan pendukung yang akan menghasilkan sebuah teori. (pengajar.co.id, 2018). Penyusun membagi menjadi beberapa bagian untuk mempermudah dalam penyusunan laporan ini, diantaranya sebagai berikut.

1. Data yang diperoleh

a. Data Primer

Data primer adalah data yang diperoleh dari hasil wawancara dengan pihak yang dianggap memahami topik atau memiliki otoritas atau persoalan (Jogiyanto, 2007).

b. Data Sekunder

Data Sekunder, yaitu data yang diperoleh dengan memanfaatkan segala informasi yang telah dihimpun oleh berbagai pihak dalam bentuk data tersajisepertibuku, laporan, tabel, grafik, data statistik dan sumber sejenis lainnya (Jogiyanto, 2007).

2. Metode Pengumpulan Data

a. Metode Observasi 
Metode Observasi adalah kegiatan pengumpulan data yang dilakukan dengan mengamati dan mencatat secara sistematik gejala - gejala yang diselidiki. (Cholid Narbuko dan Abu Achmadi 2005 : 70)

b. Metode Interview (wawancara)

Metode Interview adalah proses tanya-jawab dalam penelitian yang berlangsung secara lisan dalam mana dua orang atau lebih bertatap muka mendengarkan secara langsung informasi - informasi atau keterangan keterangan. (Cholid Narbuko dan Abu Achmadi, 2005 : 83)

c. Metode Dokumentasi

Metode Dokumentasi adalah pengumpulan data dengan memanfaatkan data sekunder, yaitu memanfaatkan semua informasi yang diperlukan yang sebelumnya telah ada atau telah dihimpun oleh pihak lain. (Sahudiyono, 2004)

3. Metode Analisis Data

Dalam menganalisa dan penyusunan menggunakan metode Analisa Deskriptif, Analisis Deskriptif adalah suatu laporan yang hanya terbatas pada apa yang tampak dan terdengar saja adalah besifat deskriptif. Untuk mengubahnya menjadi analisis, maka penyusun harus lebih dalam., guna mengetahui apa yang terdapat di belakang fakta dari yang terlihat atau terdengar tersebut. Dengan kata lain harus meneliti hubungan sebab akibat antara fakta dan meneliti pula faktafakta dan meneliti fakta-fakta yang menyertai terjadinya suatu peristiwa. (Cholid Narbuko dan Abu Achmadi, 2005 : 44).

\section{PEMBAHASAN}

\section{Tanggung Jawab PT Atho Tama}

Dalam pembahasan ini, penyusun praktik kerja melakukan praktik kerja di PT. Atho Tama Pusat Jakarta Utara yang bergerak di bidang jasa pelayaran bongkar muat. Sesuai dengan ketentuan perusahaan, penyusun praktik secara keseluruhan melakukan waktu kerja 3 (tiga) bulan di bidang tersebut. Dengan demikian, sesuai praktik yang telah dilaksanakan penyusun menyusun laporan hasil praktik kerja di bidang pembongkaran. Pembahasan ini meliputi hal-hal yang terdapat dalam rumusan masalah di atas yaitu Bagaimana keefektifan jasa bongkar muat general cargo yang dilakukan di PT. Atho Tama Jakarta Utara.

Berikut merupakan gambar tentang tanggung jawab PBM dalam kegiatan bongkar di Pelabuhan Tanjung Priok Jakarta Utara. 


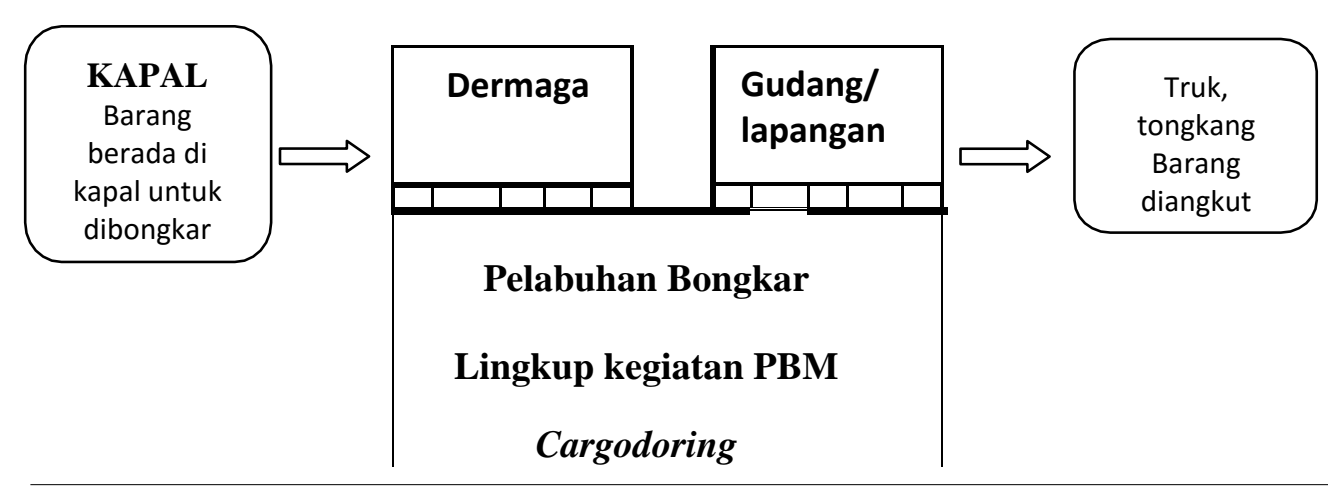

\section{Stevedoring}

A
B

Gambar 1: Tanggung jawab PBM PT. Atho Tama

Delivery

C

(Sumber: Diolah penyusun, 2020)

Berdasarkan tanggung jawab perusahaan bongkar muat, maka PT. Atho Tama yang bertindak sebagai PBM di Pelabuhan Tanjung Priok mempunyai tanggung jawab dan prinsip-prinsip sendiri dalam kelancaran kegiatan pembongkaran serta keamanan, keselamatan barang dan pekerja.

Adapun batas-batas tanggung jawab dari PBM PT. Atho Tama seperti pada gambar diatas menjelaskan bahwa mulai dari kegiatan stevedoring barang-barang yang berada didalam palka kapal, akan dibongkar kemudian barang diangkat menggunakan shipcrane sampai barang tersebut berada di dermaga, atau pun Ship to Ship. Selanjutnya kegiatan cargodoring yaitu pengangkatan barang yang berada di dermaga diangkat menggunakan forklift untuk dibawa ke gudang/lapangan penumpukan.

Setelah barang berada di gudang/lapangan penumpukan, pemilik mengambil barangnya dengan syarat dan biaya-biaya yang ditanggung sudah lunas dan sudah terbebas dari biaya apapun. Kemudian pemilik barang baru bisa mengambil atau mengeluarkan barangnya dari gudang/lapangan penumpukan dan barang akan diangkat menggunakan forklift untuk selanjutnya kegiatan trucking. Namun kegiatan tersebut beda dengan proses kegiatan Ship to Ship, Cargo yang di bongkar dari kapal langsung ke tongkang dan akan di bawa ke consignee tanpa harus di bongkar ke dermaga.

PT. Atho Tama bertanggung jawab seutuhnya pada saat pembongkaran, setelah barang sampai di lapangan penumpukan, PT. Atho Tama tidak lagi bertanggung jawab bila mana terjadi kerusakan barang yang di sebabkan oleh faktor-faktor tertentu diluar kegiatan bongkar muat.

Berikut ini merupakan gambaran alur/prosedur bongkar yang dilakukan oleh PT. Atho Tama. 


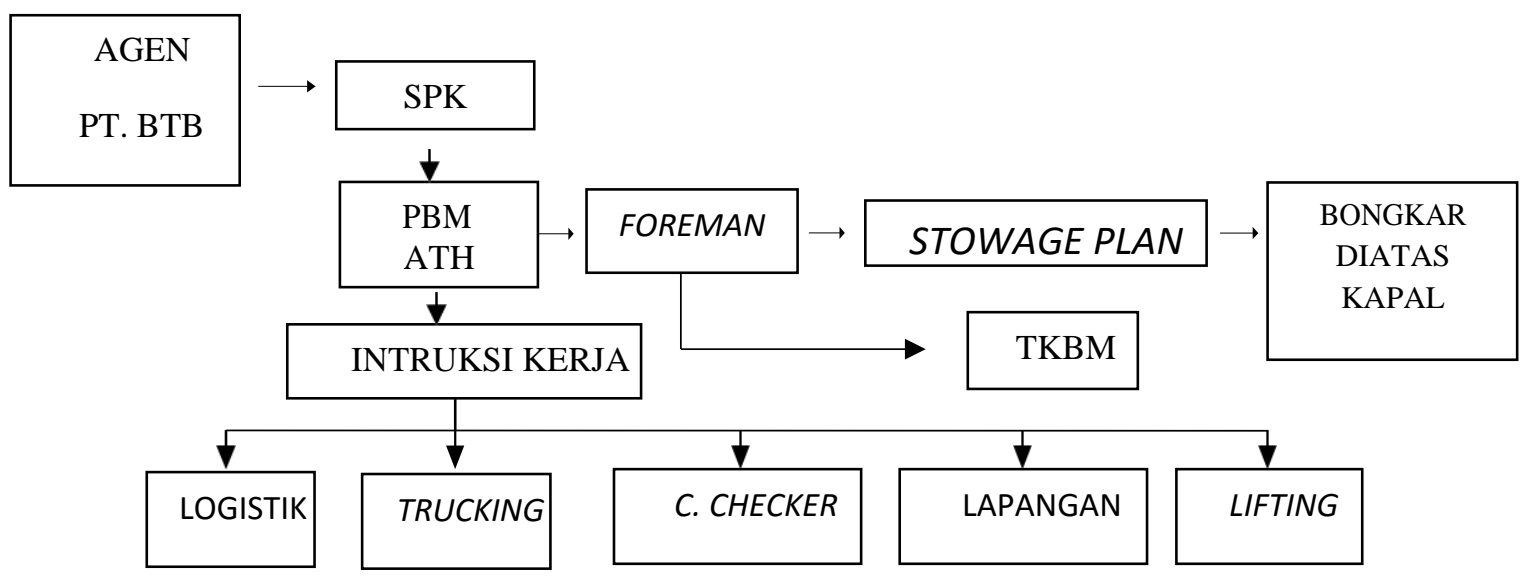

\begin{tabular}{|c|c|c|c|c|}
\hline $\begin{array}{c}\text { ALAT-ALAT } \\
\text { BONGKAR }\end{array}$ & $\begin{array}{c}\text { ARMADA } \\
\text { TRUCK }\end{array}$ & $\begin{array}{l}\text { MEMBUAT } \\
\text { DOKUMEN } \\
\text { BONGKAR }\end{array}$ & $\begin{array}{c}\text { MEMPERSIAPKAN } \\
\text { LAPANGAN } \\
\text { PENUMPUKAN }\end{array}$ & ALAT \\
BERAT \\
\hline
\end{tabular}

Gambar 2: Prosedur Dan Tahapan Bongkar

(Sumber: Diolah penyusun, 2020)

Perhitungan yang diambil oleh penyusun ketika wire sling sudah terpasang ke muatan didalam palka dan lepas wire sling ketika muatan sudah mendarat di Tongkang.

Di palka 1 Terdapat 2 cargo yang berada di Twin deck, dan cargo tersebut yang akan di bongkar terlebih dahulu, Bongkar 1 cargo Shell Assembly ke tongkang (Barge), Gross Weight 32, 381.0 Kgs, $353.90 \mathrm{M}^{3}$ start Pukul 19.30 dan mendarat di tongkang pukul 20.05 WIB, pembongkaran cargo pertama memakan waktu 35 menit untuk melakukan proses pembogkaran. Dari kegiatan pembongkaran pertama dapat disimpulkan bahwa kegiatan lebih menjuru ke safety cargo, yang berarti kegiatan sangat memegang pentingnya muatan agar muatan tetap aman tanpa terbentur dinding palka dalam proses kegiatan pembongkaaran, namun hal itu tidak menutup kemungkinan untuk TKBM yang bekerja di tongkang maupun di palka, TKBM tetap menggunakan APD dengan posedur yang sudah berlaku. Pembongkaran berjalan dengan lama(memakan waktu lama) karena pihak kapal dan PT. Atho Tama ingin barang dan orang yang bekerja aman, dan selamat.

Setelah cargo pertama telah di bongkar, mulai bongkar cargo satu lagi disebelah cargo Shell Assembly, yaitu HRSG Stack seperti gambar di atas yaitu Gross Weight HRSG Stack 24,393 Kgs, $156.28 \mathrm{M}^{3}$, proses pembongkaran dari kapal ke tongkang start pukul 20.50 WIB, dan mendarat di tongkang pukul 21.05 WIB dengan selamat dan aman.

Dibagian Twin deck sudah selesai terbongkar ke tongkang, dan kemudian Foreman dan TKBM keluar dari Palka karena Pihak kapal akan membuka pontoons bagian Lower Hold. Dalam proses kegiatan pembongkaran MV. 
Courage memiliki keunggulan dalam membuka pontoons, yaitu dengan menggunakan Transtainer Ship Crane, Membuka Pontoons 2x lebih cepat dari kegiatan kapal lainnya. Setelah kegiatan membuka pontoons selesai, mulailah untuk membongkar cargo ketiga pada pukul $23.10 \mathrm{WIB}$, dan mendarat pukul 23.25 WIB. Discharge Activity Ship To Ship in The First Palka well done at 23.35 WIB, dan dilanjut cutting \& Unlashing LH hingga pukul 23.59 WIB.

Dari kegiatan pembongkaran ketiga, terlihat sedikit perbedaan di bagian waktu yang dimana pembongkaran cargo memakan waktu yang begitu singkat, hal ini dikarenakan kegiatan pertama ketika melakukan pemasangan sling, kapal melakukan aktivitas Ballast, Ballast air yang dilakukan pihak kapal ketika proses membongkar muatan hanya sekali dalam membongkar 3 cargo atau 2 cargo, tergantung berat dan ukuran cargo yang dibongkar.

The second Barges, 19 Maret 2020. (Barge Sun Lion III), Tongkang sandar dan merapat ke MV. BBC COURAGE pukul 06.30 Sebelum kegiatan bongkar muat berjalan, persiapan alat alat PT Atho Tama, dan PT Deugro diangkut ke tongkang dan ke palka. Kegiatan Pembongkaran Ship to Ship start pukul 08.35, Bongkar dan muat ke tongkang well done pukul 11.30, lanjut kegiatan cuting dan unlashing selesai pukul 13.00 WIB

Dari analisis data diatas, penyusun mengkaji sedikit perhitungan kegiatan bongkar muat General Cargo, perhitungan seperti berikut:

Diketahui $=$ Gross Weight: $32,381.0 \mathrm{Kgs} /$ cargo Jam Kerja: 8 Jam (7 jam untuk pengoperasian Kegiatan BM, 1 jam

untuk istirahat) 1 jam: 60 Menit $/$ jadi, 7 x 60 Menit $=420$ Menit Durasi Bongkar/Cargo $=30$ menit

Hari pertama MV. Courage membongkar 7 Cargo, kegiatan berlangsung di shift 2 pukul 19.30 WIB.

Penyelesaian:

$$
\begin{aligned}
\text { Jam Kerja } & =\text { Waktu BM/Cargo x Gross Weight/Cargo } \\
& =420 \text { menit }: 30 \text { menit } \times 32,381.0 \mathrm{Kgs} \\
& =453 \mathrm{Ton} / \mathrm{Jam}
\end{aligned}
$$

Penyusun juga mengambil sedikit perbandingan pembongkaran muatan dari PT Atho Tama sendiri, yang pertama data sebagai berikut:

PBM, PT. Atho Tama 18 Januari 2020 MV. BBC AQUAMARINE

shift 1 pukul $08.00-16.00$, shift 2 pukul $16.00-23.59$, shift 3 pukul 00.00 - 08.00 Muatan yang akan di bongkar adalah Frame, Bundle, Pallet, Box.

Stavedore Activity start at 14.45 WIB, masuk di shift 1, Perhitungan sebagai berikut: Diketahui $=$ Gross Weight: $27,128 \mathrm{Kgs} /$ cargo 
Jam Kerja: 8 Jam ( 7 jam untuk pengoperasian Kegiatan

$\mathrm{BM}, 1$ jam untuk istirahat) 1 jam: 60 menit/jadi, 7 x 60

menit $=420$ menit

Durasi Bongkar/Cargo $=20$ menit

Hari pertama MV. BBC AQUAMARINE membongkar 20 Pkgs

hingga pukul 23.59, tersisa 29 Pkgs yang akan dibongkar pada 19

Januari 2020, kegiatan berlangsung di shift 1 pukul 14.55 WIB.

Penyelesaian:

Jam Kerja = Waktu Bongkar/Cargo $\mathrm{x}$ Gross Weight/Cargo

$=420$ menit $: 20$ menit $\times 27,128 \mathrm{Kgs}$

$=569 \mathrm{Ton} / \mathrm{Jam}$

Data kedua sebagai berikut:

PBM, PT. KALUKU 2 Januari 2020 MV. BBC ICE LAND

shift 1 pukul $08.00-16.00$, shift 2 pukul $16.00-23.59$,

shift 3 pukul 00.00 - 08.00 Muatan yang akan di bongkar

adalah Frame, Bundle, Pallet.

Stavedore Activity start at 14.55, masuk di shift 1.

Perhitungan sebagai berikut: Diketahui $=$ Gross Weight:

$21,188 \mathrm{Kgs} /$ cargo

Jam Kerja: 8 Jam (7 jam untuk pengoperasian Kegiatan

$\mathrm{BM}, 1$ jam untuk istirahat) 1 jam: 60 menit / jadi, 7 x 60

menit $=420$ menit

Durasi Bongkar/Cargo $=10$ menit

Hari pertama MV. BBC ICE LAND membongkar 12, kegiatan

berlangsung di shift 1 pukul 14.55 WIB. Penyelesaian: Jam Kerja = Waktu

Bongkar/Cargo x Gross Weight/Cargo

$=420$ menit : 10 menit $\times 21,188 \mathrm{Kgs}$

$=889 \mathrm{Ton} / \mathrm{Jam}$

Dari ketiga data pembongkaran diatas, penyusun dapat menyimpulkan bahwa keselamatan cargo dan keselamatan pekerja sangat lah berpengaruh terhadap efisiensi waktu, yang dimana PT. Kaluku membongkar satu cargo berdurasi 10 menit dengan berat cargo 21,188 Kgs/cargo; sedangkan PT. Atho Tama MV. Courage membongkar satu cargo berdurasi 30 menit dengan berat cargo 32,381.0 Kgs/cargo, dan MV. Aquamarine membongkar satu cargo berdurasi 20 menit dengar berat cargo $27,128 \mathrm{Kgs} /$ cargo.

Dari proses bongkar muat General Cargo yang telah penyusun saya amati, kinerja Ship to Ship maupun kegiatan bongkar ke lapangan, atau muat ke barge(tongkang), bahwa kegiatan dominan mengutamakan keselamatan dalam kinerja bongkar muat, yaitu ke cargo dan kegiatan berjalan dengan baik tanpa ada hambatan sedikit pun. Hal yang membuat kegiatan bongkar cargo lama adalah kepentingan cargo dalam proses kinerja pembongkaran, setiap kapal lebih mementingkan keselamatan kerja dan juga keamanan dan keutuhan cargo, Kegiatan berkinerja sehati hati mungkin agar cargo tidak rusak terbentur dinding kapal atau ke bagian lainnya. 
Data perhitungan pembongkaran General Cargo yang telah dianalisa penyusun yakin berporos pada metode kuantitatif yang berarti perhitungan data angka-angka yang ditambahkan penekanan terhadap pengukuran hasil yang objektif disertai analisis real dari lapangan.

\section{PENUTUP}

\section{Kesimpulan}

PT Atho Tama berkinerja membongkar General Cargo dari awal pemasangan wire sling sampai mendarat dan lepas wire sling di barge atau ke dermaga, hal ini mencakup ballast, pemasangan wire sling, serta lepas wire sling. Faktor yang sangat mempengaruhi keterlambatan atau menghambat kegiatan pembongkaran yaitu ketika proses membongkar Cargo; kapal melakukan ballast; cuaca yang buruk. Proses pembongkaran muatan General Cargo berkinerja dengan pedoman safety cargo, yang mengutamakan keselamatan dalam kinerja bongkar muat yaitu ke cargo. Setiap kapal lebih mementingkan keselamatan kerja namun disisi lain pihak kapal lebih lagi mementingkan keamanan muatan ketika sedang mengoperasikan pembongkaran ke dermaga maupun ke tongkang(barge).

\section{DAFTAR PUSTAKA}

Cholid Narbuko, Abu Achmadi, 2005, Metode Penelitian, Bumi Aksara: Jakarta. Lasse, D.A., Dr., 2016, Manajemen Muatan, Aktivitas Rantai Pasok di Area Pelabuhan, PT Raja Grafindo Parsada: Jakarta.

Suyono, RP., Capt., 2005, Shipping, Pengangkutan Intermodal Ekspor Impor elalui Laut, PPM: Jakarta.

Peraturan Mentri 152 Tahun 2016. Tentang penyelenggaraan dan pengusaha bongkar muat barang dari dan ke kapal.

Peraturan Pemerintah No. 20 Tahun 2010. Tentang Angkutan Perairan.

(https://media.neliti.com/media/publications/203265-analisis-penyebabketerlambatan-bongkar.pdf) 2016. Analisis penyebab keterlambatan bongkar. Dikases tanggal 13 Desember 2019. 